Departamento de Historia Universidad de Santiago de Chile

Revista de Historia Social

y de las Mentalidades

Volumen 24, $\mathrm{N}^{\circ}$ 2, 2020: 265-290

Issn Online: 0719-4749

\title{
PATRIMONIALIZACIÓN DE ARCHIVOS Y BIBLIOTECAS HISTÓRICOS UNIVERSITARIOS: EL CASO DE LA COLECCIÓN WORMALD DE LA UNIVERSIDAD DE TARAPACÁ*
}

\author{
HERITAGIZATION IN UNIVERSITY HISTORICAL ARCHIVES AND LIBRARIES: THE CASE \\ OF THE WORMALD COLLECTION OF THE UNIVERSITY OF TARAPACÁ
}

\author{
MG. MÓNICA MORENO FALCÓN** \\ Colección Patrimonial Wormald Cruz. Universidad de Tarapacá \\ Arica, Chile \\ Email: monica moreno@hotmail.com \\ Id-Orcid: 0000-0003-1178-1546
}

DR. RODRIGO DANIEL RUZ ZAGAL Departamento de Ciencias Históricas y Geográficas. Universidad de Tarapacá.

Arica, Chile

Email:rruz@uta.cl

Id-Orcid: 0000-0002-7474-6441

\begin{abstract}
RESUMEN
El artículo reflexiona sobre cómo los cambios conceptuales en los procesos de patrimonialización han influido en las políticas de creación, preservación y uso de bibliotecas

ABSTRACT

This article reflects on how conceptual changes in heritage processes have influenced policies of creation, preservation and use of historical university libraries in northern Chile from
\end{abstract}

* $\quad$ Recibido: 11 de diciembre de 2019; Aprobado: 1 de abril de 2020.

** Artículo resultado del proceso de mejoramiento de las colecciones históricas y patrimoniales de la Universidad de Tarapacá. Implementado a través del Convenio de Desempeño financiado por el Ministerio de Educación de Chile titulado "Innovación en la Gestión Institucional del Sistema de Biblioteca de la Universidad de Tarapacá Mediante la Habilitación de un Centro de Recursos Electrónicos y un Programa de Gestión de la Información orientado al Mejoramiento de Índices de Impacto en la Docencia, Investigación y Vinculación en Alianza con Agentes Relevantes del Medio Local y Regional”. También se agradece al proyecto FONDECYT 1181290 “Arquitectura Moderna y Ciudad: obras, planes y proyectos en el laboratorio del desarrollo. Chile 1930-1980" que evalúa la inserción de la ciudad de Arica en la órbita de desarrollo a partir de la segunda mitad del siglo XX, considerando a la Universidad, su concepción y rol en dicho proceso. 
históricas universitarias en el norte de Chile desde finales del s. XX hasta la fecha. Para ello, se estudia el caso de la Colección Patrimonial

Wormald Cruz, y se analizan tres momentos clave en su devenir: la adquisición por parte de la Junta de Adelanto de Arica en 1968, el expurgo y trabajos desarrollados en los años de dictadura,

y su reciente puesta en valor como elemento

patrimonial. Así, la revisión de los cambios desarrollados permite indagar acerca de la relación establecida entre colección y usuarios locales y abre el debate en torno a las diferentes formas de entender la preservación documental.

Palabras clave: Colecciones documentales universitarias; conservación; patrimonialización; subjetividad the end of the 20th century up to the present day. Taking the Wormald Cruz Patrimonial Collection of the University of Tarapacá as a case study, three key moments in its evolution are analyzed: the acquisition by the Junta de Adelanto de Arica in 1968, the purge and works developed during the dictatorship years and its recent enhancement as a heritage element. The review of the changes developed allows us to inquire into the relationship established between collection and local users and opens debate about the different ways of understanding documentary preservation.

Keywords: University Archives; Conservation; Heritagization; Subjectivity

Cómo citar: Moreno, Mónica y Rodrigo D. Ruz Zagal. (2020). "Patrimonialización de archivos y bibliotecas históricos universitarios: El caso de la colección Wormald de la Universidad de Tarapacá". Revista Historia Social y de las Mentalidades, 24(2), 265-290. DOI: 10.35588/rhsm.v24i2.4251

\section{PATRIMONIALIZACIÓN, CONSERVACIÓN Y USO DE BIENES DOCUMENTALES EN UN CASO}

El concepto de patrimonialización hace mención a los procesos, agentes sociales y mecanismos enfocados a lograr que un determinado bien adquiera categoría patrimonial (Sánchez 196). Hablar de patrimonialización implica considerar el patrimonio como un constructo socio-político y, por tanto, entender que los proyectos de puesta en valor son espacios de conflicto en los que numerosas variables entran en juego y condicionan "qué, cómo y para quién" funcionan los elementos patrimoniales. La introducción cada vez más frecuente del término patrimonialización y de este tipo de reflexiones en los procesos de puesta en valor, entra en conflicto directo con los supuestos criterios de objetividad que, desde la disciplina de la conservación, han sido defendidos a lo largo del s. XX y principios del s. XXI. Aspectos considerados imparciales, como las temáticas, materialidades y valores patrimoniales, han sido entendidos como variables intrínsecas a los materiales que, analizadas por el especialista, permitían decidir qué debía ser conservado y delinear propuestas interventivas neutras, $y$, por tanto, ajenas a las tendencias personales de los conservadores (Muñoz, "Subjetividad y Restauración" 75-76). 
Recientemente, algunos profesionales de la conservación han incidido en la importancia de considerar también la influencia de factores que no son inherentes a las colecciones y tienen un marcado carácter subjetivo. De esta forma, la defensa de la subjetividad como componente esencial en la toma de decisiones para la preservación en colecciones documentales ha empezado a ser defendida por algunos restauradores. Su influencia ha sido notoria en el desarrollo de nuevos conceptos y metodologías de trabajo en restauración. La equiparación del restaurador a la figura del artista-intérprete (González 7; Muñoz, "Réplica a" 16), el criterio del "argumento cambiante" planteado por Muñoz (Teoría contemporánea 96-97; "Subjetividad y restauración" 86-87), o la aplicación de la filosofía del Wabi-Sabi a la restauración de documentos defendida por Crespo (87) son ejemplos relativamente recientes de ello. Las teorías de estos autores visibilizan que los significados y valores de un bien cultural son plurales y dependen en gran medida de los grupos, instituciones e individuos implicados en su patrimonialización (López 218).

A su vez, estos cambios conceptuales han ido redefiniendo tímidamente los criterios, fundamentos y formas de entender la conservación-restauración hoy en día y han abierto nuevos debates conceptuales en torno a qué y cómo debe conservarse. Algunos de ellos, como la obligación de preservar la dimensión textual y material en tanto fuentes de información indispensables (UNESCO, Memory of the World 8-9), han sido aceptados como preceptos indiscutibles por los especialistas (al menos a nivel teórico). Otros, como el acceso de la ciudadanía a la toma de decisiones en los procesos de selección y puesta en valor (Sánchez 196-198; Pinochet 1) y las pérdidas asociadas a los procesos de selección patrimonial (DeSilvey y Harrison 2-3) han generado controversia y disparidad de opiniones.

Y es que, si bien desde la disciplina de la antropología la subjetividad asociada a los procesos de patrimonialización ha sido una temática trabajada desde la década de 1990 por los estudios críticos del patrimonio; lo cierto es que hasta fechas mucho más recientes, este tipo de planteamientos raramente han sido incorporados a la práctica por parte de los restauradores y otros especialistas encargados de la valorización y preservación del patrimonio.

El resultado ha sido la puesta en marcha de políticas o planes de manejo de colecciones que, fundamentados en una visión sustancialista en la que los valores patrimoniales serían algo intrínseco a las colecciones, no se tendrían en cuenta los intereses de los distintos actores sociales ni la posibilidad de plantear una participación abierta en su planificación. De esta forma, el papel asignado a la ciudadanía sería el de consumidor patrimonial, siendo la figura del especialista la encargada de la toma de decisiones mediante la recuperación de los supuestos valores patrimoniales inherentes a los documentos (Quintero y Sánchez 51-52). 
Para el caso de Chile, si bien ha habido progresos considerables en la preservación y rescate de colecciones documentales (Comité Nacional de la Memoria del Mundo 14-16), todavía son escasos los debates planteados desde archivos y bibliotecas en torno a los procesos de patrimonialización y los factores subjetivos que condicionan las intervenciones efectuadas. La ausencia de especialistas en estas temáticas, especialmente en espacios alejados de la capital, así como la escasez de proyectos de investigación asociados a la preservación de acervos documentales, forman parte del complejo entramado de casuísticas que acrecientan esta problemática.

A pesar de ello, la preservación de documentos ha sido considerada una actividad técnica esencial para muchas Instituciones Universitarias. En este contexto, Archivos, Centros de Documentación y Bibliotecas Especiales Universitarias han sido fundadas como lugares para y desde los que desarrollar investigación y, por tanto, necesitados de colecciones documentales. Es en estos espacios donde en la práctica han surgido las áreas encargadas de la conservación de obra gráfica, libros y documentos que actualmente están inmersas en procesos de patrimonialización.

Las necesidades de los investigadores, como usuarios prioritarios, han definido las características especiales de los trabajos de preservación desarrollados. A su vez, el requerimiento de los documentos como fuentes de información indispensables para el trabajo histórico ha centrado el foco de interés en la conservación textual de los fondos y el desarrollo de propuestas de recuperación de archivos que trabajen esencialmente con la digitalización y preservación del contenido informacional tradicional de los documentos. Este tipo de situaciones son el reflejo del enorme peso que durante años han tenido el valor documental e histórico como características definitorias del patrimonio documental.

Hoy en día nos encontramos en un momento de cambio en torno a los valores asignados a este tipo de acervos y sus usuarios. A nivel internacional, las cartas de conservación y acuerdos planteados por la UNESCO $(2002,2003)$, entre otras Instituciones, son un claro reflejo de estos cambios y del interés suscitado por definir teóricamente la importancia del papel de la ciudadanía en la creación y transmisión del patrimonio (ICOMOS 5). Para el caso del Patrimonio documental, el programa Memoria del Mundo puesto en marcha por la UNESCO deja constancia de que si bien archivos y bibliotecas mantienen su valor documental, también han adquirido un valor cultural y simbólico como espacios de recuerdo y memoria colectiva (UNESCO, Memory of the World 2-3).

Para abordar estas cuestiones desde la perspectiva del patrimonio documental, resulta interesante rescatar el ejemplo expuesto por Muñoz (Teoría 
contemporánea 62): cuando un archivo se quema, un grupo considerable de personas (mucho mayor al de los usuarios reales) considera esta situación como una pérdida cultural de gran magnitud. Este escenario visibiliza el hecho de que las comunidades asignan un gran valor cultural a los archivos a pesar de que desconozcan qué contienen o cuál es su utilidad histórica real. Sí conocen, en cambio, y valoran la importancia de preservar la historia local, y depositan su confianza en los especialistas encargados del trabajo con esos materiales. Esto es lo que se conoce a nivel teórico como el valor simbólico asignado a la creación del patrimonio (Muñoz, Teoría contemporánea 61-68) y está muy relacionado con los procesos de creación de identidad.

En esta misma línea, se puede considerar que los esquemas de valores patrimoniales que presenta una institución son un claro ejemplo de factor subjetivo que condiciona las formas de proceder en la creación, conservación y uso de colecciones. Analizar y transparentar los preceptos conceptuales desde los que actúa una institución cultural permite comprender los intereses y objetivos que subyacen detrás de los planes de puesta en valor, patrimonialización y preservación desarrollados por la misma.

Es por ello que este artículo busca abordar cómo los cambios conceptuales del término patrimonio dentro de una institución, influyen en las colecciones valorizadas, las políticas de preservación de acervos históricos universitarios y la participación abierta de los distintos actores sociales implicados en las propuestas de actuación. Es decir, busca conocer de qué manera los criterios institucionales definen una forma propia y subjetiva de patrimonializar sus colecciones.

Para ello plantea el análisis del caso de estudio de la Colección Patrimonial Wormald Cruz [CPWC] (perteneciente actualmente a la Universidad de Tarapacá, Arica) mediante la revisión del archivo perteneciente a la colección y las políticas de manejo desarrolladas a nivel institucional desde su adquisición en 1968 hasta la actualidad ¿Qué tipo de colecciones y para qué se preservaron? ¿Cuáles fueron y son los valores asignados institucionalmente al acervo documental? ¿Quiénes han sido los actores involucrados en los procesos de patrimonialización? ¿Cómo se concibió su preservación? ¿Cuáles eran y son los usuarios y usos esperados?

Para intentar dar respuesta a estas preguntas, el estudio efectuado presenta una revisión crítica de los documentos de archivo conservados sobre la adquisición y gestión de la CPWC. Se trata de un conjunto de documentos administrativos que incluye la correspondencia entre el rector de la Universidad y los propietarios particulares de la Colección, los títulos extraídos en época de dictadura, los inventarios y boletines bibliográficos de la institución y los planes de actuación desarrollados en los últimos cinco años. 
Con la intención de facilitar su revisión, los documentos han sido estructurados en relación a tres momentos considerados claves para la colección: la adquisición y llegada a Arica (1968-1973); la época de dictadura (1973-1990); y el desarrollo de las políticas de puesta en valor y preservación de colecciones (1990-2019).

\section{LOS ORÍGENES DE LA COLECCIÓN PATRIMONIAL WORMALD CRUZ}

La CPWC es la colección especial de libros perteneciente a la Universidad de Tarapacá, Arica. El nombre de la unidad hace mención a la labor desarrollada en la colección por el exacadémico e historiador regional Alfredo Wormald Cruz. Actualmente se encuentra integrada al Sistema de Bibliotecas Universitario y, junto al Archivo Histórico Vicente Dagnino [AHVD] albergan el material histórico documental de la Universidad (ver figura 1).

Los documentos que hoy en día conforman la colección corresponden a parte del acervo bibliográfico perteneciente a la exsede Arica de la Universidad de Chile (1960-1981), y principalmente a la biblioteca particular de Roberto Hernández Cornejo (1877-1966) historiador, bibliófilo y periodista conocido como el historiador de Valparaíso. Como biblioteca particular es el resultado de un proceso de selección de obras efectuado por el propio Hernández, y el reflejo, por tanto, de sus gustos personales y de los métodos historiográficos de la época.

El siglo XIX es el momento en el que se conforman los principales archivos en el país y se reúnen los materiales necesarios para hacer historia desde Chile. Metodológicamente, la historiografía chilena de este contexto está enormemente marcada por el positivismo, el uso del método crítico filológico y el historiográfico narrativo. Desde esta perspectiva el acceso a los documentos, entendidos como "reflejos fieles de la historia" adquiría una relevancia especial. A nivel de temáticas, los acontecimientos militares y bélicos (especialmente la Guerra del Pacífico y el posterior proceso de Chilenización), la crónica, las memorias, y la prensa periódica histórica, son los tópicos más trabajados por los historiadores (Gazmuri 85; Galdames y Díaz 20-23)

Las características hasta aquí reseñadas quedan reflejadas en la colección de más de 14.000 textos seleccionada por Hernández. La colección se convierte, por tanto, en un espacio desde donde materializar los modos de hacer historia de finales del siglo XIX y principios del siglo XX. Las obras completas de Diego Barros Arana, Benjamín Vicuña Mackenna o los hermanos Amunátegui, entre otros historiadores de la época, conforman el grueso de la colección, que destaca sobre todo por la bibliografía relativa a la Guerra del Pacífico, la revolución del 
91'y las temáticas salitreras. Los textos sobre la historia regional de Valparaíso, el costumbrismo y la vida social, muy del gusto de Hernández, también conforman una parte considerable de la misma, así como la hemeroteca de finales del XIX y principios del XX y la colección de fotografías de época (ver tabla 1).

Ilustración 1: Colección Patrimonial Wormald Cruz, espacios de depósito de ejemplares físicos (Moreno, 2019)

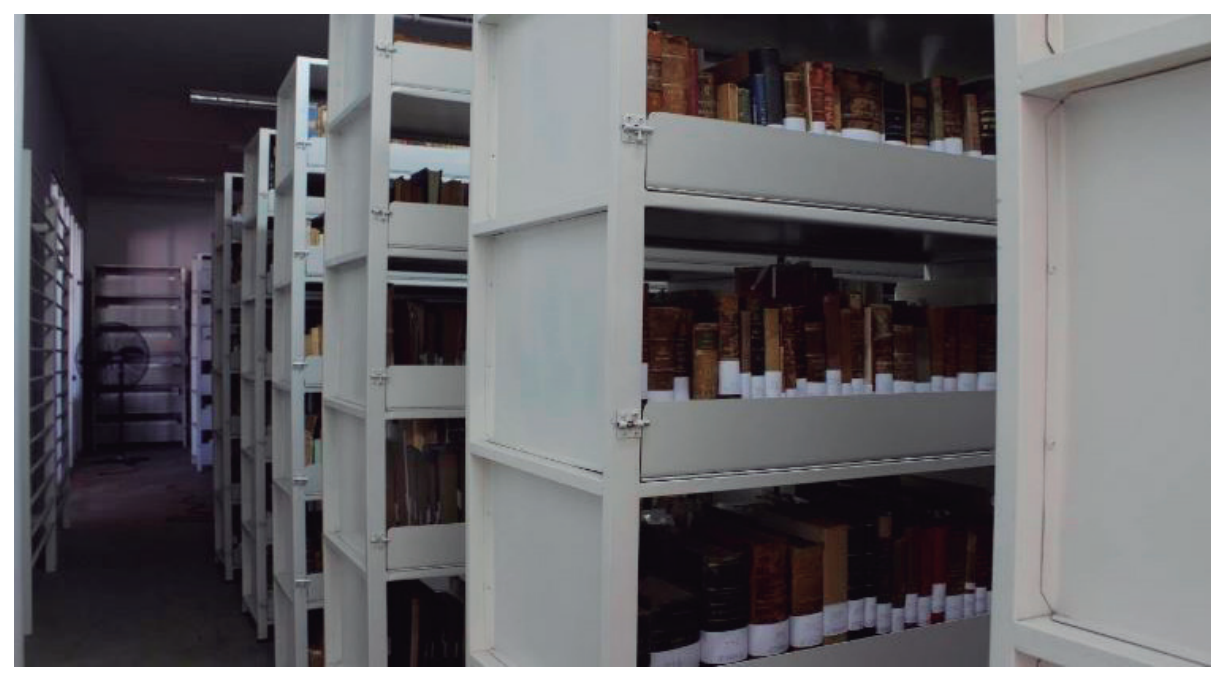

Fuente: Fondo Fotográfico CPWC

Tabla 1: Materiales y contenidos pertenecientes a la Colección Patrimonial Wormald Cruz

\begin{tabular}{|l|l|l|l|}
\hline Título & $\begin{array}{l}\text { Volumen/ } \\
\text { Materialdad }\end{array}$ & $\begin{array}{l}\text { Fechas de } \\
\text { producción }\end{array}$ & Descripción \\
\hline $\begin{array}{l}\text { North, Jhon } \\
\text { Thomas }\end{array}$ & $\begin{array}{l}\text { 36 unidades } \\
\text { documentales en } \\
\text { papel }\end{array}$ & $1877-1930$ & $\begin{array}{l}\text { Documentos emitidos por } \\
\text { empresas pertenecientes a North. }\end{array}$ \\
\hline Prensa Local & $\begin{array}{l}10 \mathrm{~m} \text {. lineales en } \\
\text { papel, 356 rollos } \\
\text { de microfilms y } \\
\text { más de 96.000 } \\
\text { imágenes digitales }\end{array}$ & $1882-1988$ & Diarios Tacna y Arica \\
\hline $\begin{array}{l}\text { Prensa } \\
\text { Nacional }\end{array}$ & $\begin{array}{l}\text { 2,5 m. lineales en } \\
\text { papel y 15 rollos } \\
\text { de microfilms }\end{array}$ & $1864-1946$ & $\begin{array}{l}\text { Diarios de Santiago, Valparaíso y } \\
\text { zona central de Chile }\end{array}$ \\
\hline
\end{tabular}




\begin{tabular}{|c|c|c|c|}
\hline $\begin{array}{l}\text { Magazines y } \\
\text { miscelaneas }\end{array}$ & $\begin{array}{l}48 \mathrm{~m} . \text { lineales en } \\
\text { papel }\end{array}$ & 1843-1999 & $\begin{array}{l}\text { Zig-Zag, Topaze, Sucesos, Corre } \\
\text { Vuela... }\end{array}$ \\
\hline $\begin{array}{l}\text { Revistas es- } \\
\text { pecializadas }\end{array}$ & $\begin{array}{l}30 \mathrm{~m} . \text { lineales en } \\
\text { papel }\end{array}$ & 1884-1999 & $\begin{array}{l}\text { Artes y Letras, Revista Chilena de } \\
\text { Historia y Geografia, Acontecer... }\end{array}$ \\
\hline $\begin{array}{l}\text { Colección } \\
\text { general }\end{array}$ & $\begin{array}{l}288 \mathrm{~m} . \text { lineales en } \\
\text { papel }\end{array}$ & $1820-1960$ & $\begin{array}{l}\text { Libros y folletos de la Biblioteca } \\
\text { privada de Hernández Cornejo }\end{array}$ \\
\hline $\begin{array}{l}\text { Sección } \\
\text { salitre }\end{array}$ & $\begin{array}{l}2 \mathrm{~m} \text {. lineales en } \\
\text { papel }\end{array}$ & $1827-1973$ & $\begin{array}{l}\text { Monografías y folletos del salitre } \\
\text { publicados entre el s. XIX y } \\
\text { principios del XX. Modificaciones } \\
\text { de las políticas estatales, técnicas } \\
\text { de producción, ritmos de } \\
\text { exportación... }\end{array}$ \\
\hline $\begin{array}{l}\text { Sección } \\
\text { Guerra del } \\
\text { Pacífico }\end{array}$ & $\begin{array}{l}3 \mathrm{~m} \text {. lineales en } \\
\text { papel }\end{array}$ & 1863-1979 & $\begin{array}{l}\text { Monografías y folletos } \\
\text { pertenecientes a los conflictos } \\
\text { limítrofes entre Bolivia y Chile y } \\
\text { el posterior desarrollo de la Guerra } \\
\text { del Pacífico. Relatos históricos, } \\
\text { crónicas, epistolarios, novelas y } \\
\text { albums fotográficos }\end{array}$ \\
\hline $\begin{array}{l}\text { Sección } \\
\text { Valparaiso }\end{array}$ & $\begin{array}{l}2 \mathrm{~m} \text {. lineales en } \\
\text { papel }\end{array}$ & 1848-1948 & $\begin{array}{l}\text { Historia urbana, social y cultural } \\
\text { de la ciudad }\end{array}$ \\
\hline $\begin{array}{l}\text { Sección } \\
\text { obras } \\
\text { Hernández } \\
\text { Cornejo }\end{array}$ & $\begin{array}{l}2 \mathrm{~m} \text {. lineales en } \\
\text { papel }\end{array}$ & 1894-1952 & $\begin{array}{l}\text { Obras publicadas por Roberto } \\
\text { Hernández Cornejo }\end{array}$ \\
\hline $\begin{array}{l}\text { Sección } \\
\text { Libros } \\
\text { Antiguos }\end{array}$ & $\begin{array}{l}3 \mathrm{~m} \text {. lineales en } \\
\text { papel }\end{array}$ & $1695-1820$ & $\begin{array}{l}\text { Libros impresos con anterioridad } \\
\text { a } 1820 \text { en Lima, Santiago, } \\
\text { Valparaíso, Madrid, Barcelona, } \\
\text { Valencia y otras capitales } \\
\text { europeas. Obras políticas, } \\
\text { religiosas, geográficas, jurídicas y } \\
\text { gramaticales. }\end{array}$ \\
\hline $\begin{array}{l}\text { Colección de } \\
\text { fotografías y } \\
\text { postales }\end{array}$ & $\begin{array}{l}1500 \text { fotografías } \\
\text { en papel }\end{array}$ & $\begin{array}{l}\text { s. XIX y } \\
\text { XX }\end{array}$ & $\begin{array}{l}\text { Colección privada de fotografías y } \\
\text { postales del historiador Hernández } \\
\text { Cornejo }\end{array}$ \\
\hline
\end{tabular}

Fuente: Moreno, 2019. A partir de datos aportados por la Colección Patrimonial Wormald Cruz. 


\section{LA ADQUISICIÓN}

La llegada de la colección a la ciudad de Arica tiene lugar en 1968 cuando, tras el fallecimiento de su propietario, pasa a convertirse en la primera colección especial de la Universidad.

En este contexto "la ciudad de Arica, ubicada al norte de Chile experimentó [...] uno de los procesos de descentralización más notables que llevara a cabo el gobierno Chile en una zona extrema" (Ruz et al., Junta de Adelanto 13). Como consecuencia de la otorgación de atributos arancelarios se creó, primeramente, el puerto libre de Arica (1953-1958) y, posteriormente, se conformó la Junta de Adelanto de Arica [JAA] (1958-1976). Las funciones de esta última serían esencialmente descentralizar los servicios públicos y propiciar el comercio, la industria y el turismo de la zona. Como resultado de estas medidas, la población de la ciudad creció exponencialmente y para dar salida a este incremento poblacional se generó una política de planificación urbana que no solo pretendía solucionar las necesidades generadas desde la ciudad, sino que también proyectaba su crecimiento futuro.

Este es el momento en el que se asienta en la ciudad la sede Arica de la Universidad del Norte y se construyen los edificios del campus universitario. Los procesos de patrimonialización desarrollados plantean como punto de partida la adquisición de colecciones especiales que ya poseen un reconocimiento como elementos históricos valiosos. Por medio del convenio efectuado entre la Universidad y la JAA se transfieren los fondos económicos necesarios para la adquisición de la Biblioteca Hernández Cornejo por parte de la extinta Universidad. Una vez efectuada la compra a la familia de Hernández, la colección es trasladada desde la casa del historiador en Valparaíso hasta la sede de la Universidad del Norte en Arica, donde se suma a los ejemplares de la Biblioteca General Universitaria.

Así pues, la adquisición de la Biblioteca de Hernández se asocia a los procesos de modernización de la región de Arica y de descentralización de la educación en Chile; pero a su vez refleja la intencionalidad de fomentar el desarrollo de narrativas y discursos universitarios locales afines a los generados desde el centro del país. La carta emitida en marzo de 1968 por Agustín Sánchez, rector de la Universidad del Norte, en agradecimiento a la familia de Hernández por la adquisición efectuada, deja constancia de la funcionalidad y usos esperados para la colección:

El haber traído esta biblioteca a Arica es un incremento para el desarrollo cultural del Norte de Chile, pero mucho más aún por 
el hecho de poder mostrar un pasado histórico desconocido aún entre nosotros. La juventud que se forma en esta Universidad debe reconocer lo que han sido sus antepasados y los forjadores de esta Patria. La colaboración que este material nos prestará es en provecho del desarrollo del Norte Chileno. Quiero manifestarle mis agradecimientos por esta donación y su colaboración. Profesores y alumnos sabrán apreciar este material que forjará los hombres del mañana mostrándoles lo que ha sido el paso. Con la obra de su padre se ha avanzado en el desarrollo de Arica (Universidad del Norte, carta emitida por Agustín Sánchez Hurtado y enviada a Gabriel Hernández Anderson el 16 de marzo de 1968).

Si bien el valor documental es inherente a los textos desde su adquisición, resulta evidente una fuerte relación con su valor como monumento o espacio de puesta en memoria de un pasado heroico de la nación chilena en la zona norte del país. De esta forma las políticas institucionales de adquisición de colecciones se muestran acordes a los criterios internacionales de conservación de principios del siglo XX (Carta de Atenas 1) y rescatan la importancia del patrimonio como monumento y/o espacio de prestigio y reconocimiento nacional.

Los textos que conforman el grueso de la colección, resultado de la historiografía nacional del siglo XIX, reflejan una pretensión por construir una historia de Chile vinculada necesariamente a la cimentación del estado nación. La historiografía de este contexto, proclive a homogeneizar los relatos en relación a los procesos históricos nacionales, presenta una mirada posicionada desde el centro político. El interés por la historia política y militar, la exaltación del héroe de guerra, y los paralelismos efectuados entre los binomios civilización/barbarie y centro/periferia nortina, darán lugar a un relato historiográfico que acabará por invisibilizar a los actores sociales que habitan los espacios nortinos (Galdames y Díaz 20-23; Díaz et al., "Entre el Archivo" 107-109). De esta forma, los procesos de patrimonialización desarrollados institucionalmente no considerarán todavía la adquisición y revalorización de elementos locales propios.

En relación a los usuarios esperados para la colección, el paso de biblioteca particular a biblioteca universitaria condicionará, al menos a nivel teórico, la ampliación del número de usuarios de la colección. En la práctica, el retraso por parte de la Universidad del Norte en la realización de los trabajos técnicos de inventariado, clasificación y catalogación, requisitos previos para poder facilitar el acceso y uso de los ejemplares, imposibilitó el acceso de la comunidad universitaria a los textos. El resultado será una colección que permanecerá en cajas durante años, antes de pasar a formar parte efectiva de la biblioteca universitaria. 


\section{EXPURGO Y TRABAJOS EN DICTADURA}

Los acontecimientos de septiembre de 1973 suponen un cambio considerable en las políticas institucionales planificadas para el acervo documental. El Archivo de la colección deja constancia del retiro de libros, folletos, revistas y periódicos pertenecientes al grueso de la biblioteca universitaria por el Servicio de Inteligencia. A su vez, también se conservan documentos que analizan el material bibliográfico recolectado en Arica en el Regimiento de Rancagua. Estos establecen cifras aproximadas de 8000 libros, 3000 revistas, 2500 folletos y 6000 ejemplares de los diarios La Nación, El Popular, Puro Chile y El Siglo, valoradas en un total de 3.203.090 escudos (Lista de publicaciones periódicas recolectadas 1973; Libros retirados por el servicio de inteligencia 1973). Este tipo de acciones quedan enmarcadas en un conjunto general de operaciones represivas desarrolladas por el nuevo régimen dispuesto a eliminar las producciones culturales del contexto de la Unidad Popular y controlar cualquier intento de disidencia.

Paralelamente al expurgo efectuado en la colección, las cartas emitidas por los familiares de Hernández en 1974 al Rector de la Universidad del Norte (carta emitida por Gabriel Hernández Anderson y enviada al coronel Hernán Danyau Quintana el 5 de Enero de 1974), al Gerente General de la JAA (carta emitida por Gabriel Hernández Anderson y enviada a Teodoro Schmidt el 5 de Enero de 1974), al Alcalde de la Ilustre Municipalidad (carta emitida por Gabriel Hernández Anderson y enviada a Manuel Castillo Ibaceta el 5 de Enero de 1974) y al Gobernador Departamental-Jefe Militar de la Guarnición (carta emitida por Gabriel Hernández Anderson y enviada a Odlanier Mena Salinas el 5 de Enero de 1974), dejan constancia de las problemáticas que la falta de trabajo técnico bibliotecológico está generando en la colección y demandan su registro y apertura a la comunidad universitaria.

En este contexto, surge el Centro de Investigación y Documentación Histórica [CIDH] de la Sede Arica de la Universidad del Norte que, bajo la dirección de Alfredo Wormald Cruz, queda encargado del cuidado personal de la colección. Desde este espacio se desarrollará el conjunto de prácticas e iniciativas para la valorización y preservación de la colección especial. Los documentos son separados del resto de ejemplares que conforman la Biblioteca General y renombrados como Colección Histórica.

Desde el CIDH, un equipo compuesto por historiadores y bibliotecarios comenzará a desarrollar las labores de inventariado, clasificación y catalogación, así como la emisión de boletines bibliográficos que agrupaban por secciones las temáticas consideradas más relevantes. La guerra del Pacífico, la revolución de 
1891 y las cuestiones salitreras seguirán siendo consideradas las temáticas más relevantes a las que se sumarán otras consideradas de especial utilidad para las carreras desarrolladas desde la Universidad, como las técnicas agropecuarias y la literatura.

En este contexto surge desde la institución un cuestionamiento acerca de los valores patrimoniales asociados a los documentos históricos que albergan las colecciones especiales ¿Cuál es el valor de las colecciones? ¿Qué libros o ejemplares deben formar parte de ellas? ¿Pueden estos acervos aumentar en número sus ejemplares? ¿Cuáles son los criterios para seleccionar las nuevas adquisiciones? Todas estas son preguntas que se irán perfilando dentro de las políticas institucionales de la Universidad y tratarán de dar respuesta a la necesidad de adquirir nuevos documentos que resulten funcionales a la investigación.

A partir de ahora, la institución universitaria entenderá la colección como un espacio abierto que irá creciendo e incluyendo nuevos materiales tanto bibliográficos como archivísticos. Ejemplo de ello será la adquisición del fondo John North por parte de la Universidad del Norte en el año 1977. Este fondo está compuesto por un conjunto de 244 documentos relativos a escrituras públicas otorgadas en Chile e Inglaterra a partir del año 1870, cartas y papeles diversos vinculados a la figura de John Thomas North. En su gran mayoría son contratos de compraventa, delegación de poderes, finiquitos, pólizas y seguros relacionados con la Oficina Buen Retiro, Compañía Primitiva y Campbell Outram and Company, Lockett Brothers and Company, Colorado Nitrate Company, The Liverpool Nitrate Company y The Alianza Company, que fueron descubiertos casualmente en una casona de Iquique. Su adquisición muestra cambios en las actividades asociadas a los procesos de patrimonialización institucionales que se ven reflejadas en un incipiente interés por reunir nuevas fuentes primarias que permitan generar estudios desde la Universidad y fomentar nuevas líneas de investigación a partir de documentos locales.

En el año 1981 el Ministerio de Educación Pública en Chile crea la Universidad de Tarapacá. Esta será el resultado de la fusión del Instituto Profesional de Arica (ex sede Arica de la Universidad de Chile) con la Universidad del Norte, sede Arica. En este contexto, los documentos bibliográficos de ambas Instituciones con valor histórico pasan a conformar el acervo documental conocido como la CPWC. El nuevo nombre asignado guardará relación con el historiador que se encargó de su gestión desde el CIDHE.

Paralelamente en el año 1986 nace el AHVD y en el año 1987 la facultad de Estudios Andinos. Este es el momento cuando se delinea un perfil profesional 
en Arica, encargado de investigar acerca de la historia, antropología, arqueología y geografía local. Es ahora cuando la biblioteca de Hernández comienza a definirse con mayor peso como una colección especial dentro de la Universidad de Tarapacá. Esta será valorada especialmente por su función documental y contará con unos usuarios especializados y centrados en el desarrollo de investigaciones históricas desde el norte del País.

En relación a la conservación de la colección, es en esta época que los efectos de los sismos y los robos supondrán considerables pérdidas. Ejemplo de ello será el Fondo John North, que, si bien estuvo compuesto inicialmente por 244 documentos, actualmente solo conserva 33 (CIDH, Boletín bibliográfico: Papeles de J. TT 1977). A su vez, el exceso de exposición a la luz solar y las altas temperaturas registradas en un clima desértico como el de Arica generarán graves problemas de friabilidad en una colección compuesta esencialmente por papeles de baja calidad técnica y, por lo tanto, especialmente vulnerable y tendente al deterioro.

A pesar de ello, las políticas institucionales de valorización de las colecciones especiales, se centrarán en el desarrollo de procesos técnicos bibliotecológicos y no considerarán necesario emprender actividades de conservación que minimicen el deterioro que el paso del tiempo empezaba a generar en los ejemplares. Las labores de reparación seguirán siendo consideradas una actividad más de los bibliotecarios que, al igual que en el caso de la colección general, guillotinarán, reencuadernarán, y repararán con cinta adhesiva los ejemplares dañados pertenecientes a la colección especial.

A su vez, en relación a las políticas de uso de las colecciones, nos encontramos con una visión institucional muy acorde a los criterios dictados por la carta de Conservación de Atenas de 1931. El usuario, considerado en muchas ocasiones un peligro-factor de degradación, junto al papel predominante asignado a los valores históricos-documentales de las colecciones especiales, definieron las políticas de uso de la época. La necesidad de imponer normativas de acceso restrictivas que favoreciesen la conservación, la escasez de especialistas en conservación en el contexto local, y el surgimiento de historiadores locales vinculados a la gestión de dichas colecciones, serán las causas principales del surgimiento de políticas de consulta restrictivas que motivarán un uso casi exclusivo de las colecciones por historiadores. 


\section{EL CAMBIO DE SIGLO Y LA PUESTA EN VALOR}

A partir de la década de 1990, el retorno a la democracia y el desarrollo de investigadores-especialistas a nivel local promovió el desarrollo de nuevos usos y propuestas de gestión de los archivos y colecciones documentales.

Si bien a finales de la década de 1960, la adquisición de la colección reflejaba un interés por custodiar materiales documentales que simbolizasen un pasado nacional heroico, con el cambio de siglo se va constatando una mayor inclinación a las temáticas regionales. La integración de los historiadores locales en los procesos de selección y ampliación de las colecciones especiales, la redefinición de los valores asociados a las mismas y la forma en que son interpretadas son indicativos de la descentralización de los procesos de patrimonialización desarrollados a finales del siglo XX.

Los estudios históricos desarrollados introdujeron cambios teóricos, temáticos y metodológicos. En este aspecto, los enfoques culturalistas propondrán nuevas formas de acercarse a temáticas trabajadas tradicionalmente (Galdames y Díaz 23-24; Ruz et al., "Historia, patrimonio y fotografía" 102) favorecerán la recuperación y valorización de fuentes documentales relativas a los procesos culturales locales y conllevarán cambios en los usos asignados a las colecciones. Ante esta situación, la colección especial pasará de ser considerada un conjunto de fuentes textuales necesarias para hacer historia, a un espacio desde donde hacer historia crítica, revisar y ampliar las fuentes tradicionales.

En este momento, la hemeroteca histórica empezará a ser trabajada intensamente por los especialistas, así como los libros relativos a los procesos de chilenización del Norte Grande. Las relecturas y nuevos usos asignados a la colección permitirán el desarrollo de proyectos de investigación en relación a la construcción de imaginarios nacionales en la nueva frontera norte de Chile, las hegemonías discursivas de la prensa fronteriza, los estereotipos nacionales y étnicos en las publicaciones magazinescas, o las representaciones de la cultura nacional peruana y chilena en la zona de frontera (Ruz et al., "Exotización y alterización" 23; Ruz et al., "La comisión plesbiscitaria" 193; Ruz et al., "Magazines Zigzag" 135).

En este sentido, se observa un cambio de percepción institucional en relación a los documentos que poseen un mayor valor cultural y que, por lo tanto, deben ser patrimonializados y conservados. Los cambios sufridos en las políticas institucionales, guardan una estrecha relación con la influencia de los estudios críticos del patrimonio (desarrollados desde la antropología en esta época) y con el paso que, desde la conservación, se da del concepto de 
patrimonio como conjunto de bienes histórico-artísticos monumentales, al de patrimonio entendido como ente cultural.

A su vez, el posicionamiento de los investigadores como gestores dentro de sus instituciones permitirá desarrollar nuevas políticas de puesta en valor y uso de los archivos, centros de documentación y repositorios digitales universitarios (Ruz y Galdames 3-5). Ante estas condiciones de cambio, archivos y colecciones bibliográficas especiales reforzarán su imagen como espacios que custodian documentos, aseguran su conservación, producen ideas y fomentan el hábito de investigación y crítica.

En el caso de la ciudad de Arica será el AHVD quien tome el liderazgo inicialmente. Estas nuevas corrientes metodológicas se verán materializadas en los intentos efectuados desde el AHVD en la adquisición, recuperación e investigación de fondos que permitan ofrecer distintas lecturas en relación a la historia local de Arica. A partir del año 2009, la recuperación de archivos fotográficos por medio de proyectos colaborativos con la ciudadanía generará nuevos fondos y favorecerá el acceso de nuevos profesionales y usuarios al Archivo Universitario. Esta será la vía para conformar el fondo Enrique Flores Reyes con material fotográfico producido por el periodista de la desaparecida JAA; el fondo Mario Gutiérrez Viveros con fotografías relacionadas a la práctica del fútbol amateur ariqueño; o el fondo Manuel Yanulaque Scorda con fotografías familiares del inmigrante griego y su esposa afro en el contexto de 1870 (ver tabla 2). 
Tabla 2: Materiales incorporados al AHVD como resultado de colaboraciones/ investigaciones

\begin{tabular}{|c|c|c|c|c|}
\hline $\begin{array}{l}\text { Tipo de } \\
\text { material }\end{array}$ & Título & $\begin{array}{l}\text { Volumen/ } \\
\text { Materialidad }\end{array}$ & $\begin{array}{l}\text { Fecha de } \\
\text { producción }\end{array}$ & Descripción \\
\hline \multirow{3}{*}{$\begin{array}{l}\text { Material de } \\
\text { archivo digital }\end{array}$} & $\begin{array}{l}\text { Aymaras } \\
\text { ciudad de } \\
\text { Arica }\end{array}$ & $\begin{array}{l}630 \text { minutos de } \\
\text { audio, archivo } \\
\text { digital *mp3 }\end{array}$ & 2012 & $\begin{array}{l}\text { Entrevistas con relatos de } \\
\text { vida de los habitantes de } \\
\text { origen aymara del sector } \\
\text { Maipú Oriente de la } \\
\text { ciudad de Arica }\end{array}$ \\
\hline & $\begin{array}{l}\text { Expampinos } \\
\text { ciudad de } \\
\text { Arica }\end{array}$ & $\begin{array}{l}1080 \text { minutos } \\
\text { de grabación. } 36 \\
\text { archivos *wav }\end{array}$ & 2011 & $\begin{array}{l}\text { Entrevistas basadas } \\
\text { en los recuerdos e } \\
\text { historias de vida de } \\
\text { aquellos que habitaron } \\
\text { la pampa salitrera y que } \\
\text { actualmente radican en } \\
\text { Arica }\end{array}$ \\
\hline & $\begin{array}{l}\text { María Ester } \\
\text { Grebe }\end{array}$ & 6 DVD & $1976-1983$ & $\begin{array}{l}\text { Piezas musicales } \\
\text { recogidas por la doctora } \\
\text { Grebe. Tarkeadas, cantos } \\
\text { en aymara, huayños, } \\
\text { relatos orales y de } \\
\text { interpretación musical, } \\
\text { entrevistas, cacharpata, } \\
\text { lakitas, cuecas, música de } \\
\text { bronces, carnavales... }\end{array}$ \\
\hline \multirow{3}{*}{$\begin{array}{l}\text { Material } \\
\text { fotográfico }\end{array}$} & $\begin{array}{l}\text { Manuel } \\
\text { Yanulaque } \\
\text { Scorda }\end{array}$ & 621 fotografías & $1890-1940$ & $\begin{array}{l}\text { Series fotográficas } \\
\text { realizadas por la familia } \\
\text { Yanulaque en la ciudad de } \\
\text { Arica y las inmediaciones } \\
\text { del sur peruano. }\end{array}$ \\
\hline & $\begin{array}{l}\text { Enrique } \\
\text { Flores Reyes }\end{array}$ & 325 fotografías & $1965-1980$ & $\begin{array}{l}\text { Acontecimientos, } \\
\text { ceremonias, } \\
\text { inauguraciones, planes } \\
\text { y políticas de la antigua } \\
\text { Junta de Adelanto de } \\
\text { Arica y la Oficina de } \\
\text { turismo de la ciudad de } \\
\text { Arica }\end{array}$ \\
\hline & $\begin{array}{l}\text { Gutierrez } \\
\text { Viveros } \\
\text { Mario }\end{array}$ & 102 fotografías & 1920-1997 & $\begin{array}{l}\text { Ligas de futbol amateur } \\
\text { local vinculadas a sectores } \\
\text { poblacionales de la } \\
\text { creciente ciudad de Arica }\end{array}$ \\
\hline
\end{tabular}

Fuente: Moreno, 2019. A partir de datos aportados por el Archivo Histórico Vicente Dagnino. 
En esta misma línea de trabajo, desde 2015, y gracias al financiamiento del Ministerio de Educación chileno, se ejecuta el proyecto "Innovación en la Gestión Institucional del Sistema de Biblioteca de la Universidad de Tarapacá", dando comienzo a las reformas de la biblioteca universitaria tendentes a mejorar las dinámicas y los espacios específicos destinados a la formación, investigación, manejo y preservación del acervo documental histórico y patrimonial del que dispone la Universidad.

Este es el momento en que se plantea a nivel institucional que el funcionamiento de los archivos y colecciones documentales históricas exige de competencias diversas, personal cualificado y espacios óptimos para asumir las responsabilidades de la preservación material de este tipo de colecciones. Esta instancia es entendida como una oportunidad de profesionalización para la institución, que pasa a contar por vez primera con una especialista en conservaciónrestauración encargada de planificar las propuestas de gestión de la colección a mediano-largo plazo. El plan de trabajo definido institucionalmente en tales circunstancias, girará en torno a tres puntos clave: la clasificación y catalogación de los ejemplares desarrollada desde el área de biblioteconomía; la conservación informacional de los textos desarrollada desde el área de digitalización; la conservación física de los ejemplares y la difusión de colecciones desarrollada desde el área de conservación.

A partir de esta fecha las políticas institucionales se vuelven más conscientes de la fragilidad de los documentos custodiados y los procesos de patrimonialización desvían su foco de atención de la adquisición y selección de colecciones documentales a la conservación de las ya existentes. El depósito se habilita con un sistema de control ambiental y se realiza un seguimiento y análisis de las condiciones registradas. Con la finalidad de estabilizar los documentos, minimizar pérdidas, evitar robos, y prevenir del deterioro mecánico en caso de sismo, se adquieren estanterías y mobiliario acorde a las necesidades de la colección.

Se habilitan amplias salas de trabajo, box de investigación, salas de consulta, un área de conservación, un laboratorio de digitalización y depósitos óptimos para el resguardo de Colecciones. Gracias no solo a la habilitación de un espacio de trabajo adecuado, sino también a la adquisición de equipos técnicos, insumos de conservación y a la conformación de un equipo interdisciplinar comienzan a realizarse de manera continuada trabajos acordes a los estándares internacionales plasmados por la UNESCO, la IFLA-PAC y la ICA.

En este momento, se da también un paso significativo en el acceso y uso de colecciones por medio del establecimiento de nexos con los directores de programas de postgrado de la institución, Magíster y Doctorado en Historia, potenciales usuarios de los materiales y de los espacios destinados naturalmente a 
la investigación. A su vez, la realización de ayudantías, prácticas y voluntariados de manera regular, así como la vinculación con los estudiantes universitarios desde el primer curso, plantean otras formas de acceder a los documentos y favorecen el desarrollo a nivel local de una ciudadanía crítica e involucrada activamente en los procesos de gestión de archivos documentales.

Paralelamente, el perfil de los usuarios de las colecciones se ha ampliado de manera considerable. La aplicación de este tipo de políticas de apertura institucionales y el empleo de las redes sociales (ver figuras 2 y 3 ) han permitido establecer un vínculo más estrecho con investigadores profesionales, estudiantes dedicados a la investigación, personas que buscan información de interés personal, o que buscan inspiración, coordinadores de visitas y visitantes informales. Los nuevos perfiles de usuarios dan cuenta del paso que se ha dado de colecciones históricas a patrimoniales, de modo que los perfiles identificados actualmente en este tipo de instituciones son similares a los identificados en estudios de segmentación del público efectuados en museos (Villaespesa).

Es en estas condiciones que la colección ha adquirido una doble función: la de un espacio de investigación y la de un espacio abierto de discusión sobre los procesos de selección, activación y preservación de acervos documentales. La convivencia de la ciudadanía y los investigadores de manera conjunta en archivo y biblioteca será clave para visibilizar el valor simbólico de los documentos como elementos memorísticos y patrimoniales, así como la importancia del investigador en la construcción de relatos históricos que posibiliten la valorización de los documentos rescatados. Asimismo, la existencia de un área de conservación posibilita realizar intervenciones y plantear propuestas de investigación asociadas a los materiales documentales, lo que a su vez expone la necesidad de contar a nivel institucional con un perfil de especialistas multidisciplinar capaz de definir conjuntamente cuáles van a ser los criterios que deben regir el trabajo con colecciones.

Actualmente y tras varios años de asesorías y colaboraciones con el Centro Nacional de Conservación y Restauración [CNCR], el archivo Central Andrés Bello [AB], y la Biblioteca Nacional de Chile [BNC], se cuenta con el espacio y el equipo necesario para comenzar a desarrollar una línea de trabajo institucional propia en preservación de colecciones. Este escenario abre la posibilidad de pensar acerca de las problemáticas reales que presentan los archivos y colecciones especiales en el contexto local. El análisis de la materialidad de los diversos fondos, el máximo respeto a los originales y la mínima intervención e idoneidad de los procedimientos aplicados se definen como los ejes fundamentales de este espacio de trabajo. Al mismo tiempo, los avances logrados en materias de digitalización de grandes formatos (Moreno y Castillo 80-90), así como las propuestas metodológicas desarrolladas en la línea 
de la gestión de riesgos (Moreno 68-79), y la evaluación de tratamientos de control de $\mathrm{pH}$, suponen los primeros aportes teóricos generados desde Arica en la preservación y gestión de colecciones documentales.

Por último, las redes de contacto establecidas con otros espacios universitarios como el área de Bibliometría o el Laboratorio de Análisis e Investigaciones Arqueométricas abren la posibilidad de desarrollar nuevas líneas investigativas centradas en el análisis de otros valores documentales distintos al textual.

Ilustración 2: Campaña de difusión en redes sociales, 2019. Colección Patrimonial Wormald Cruz.
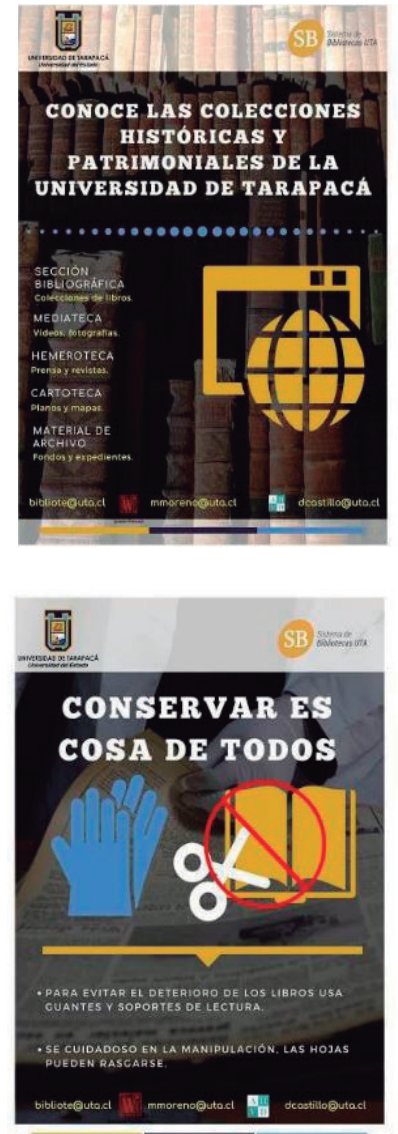
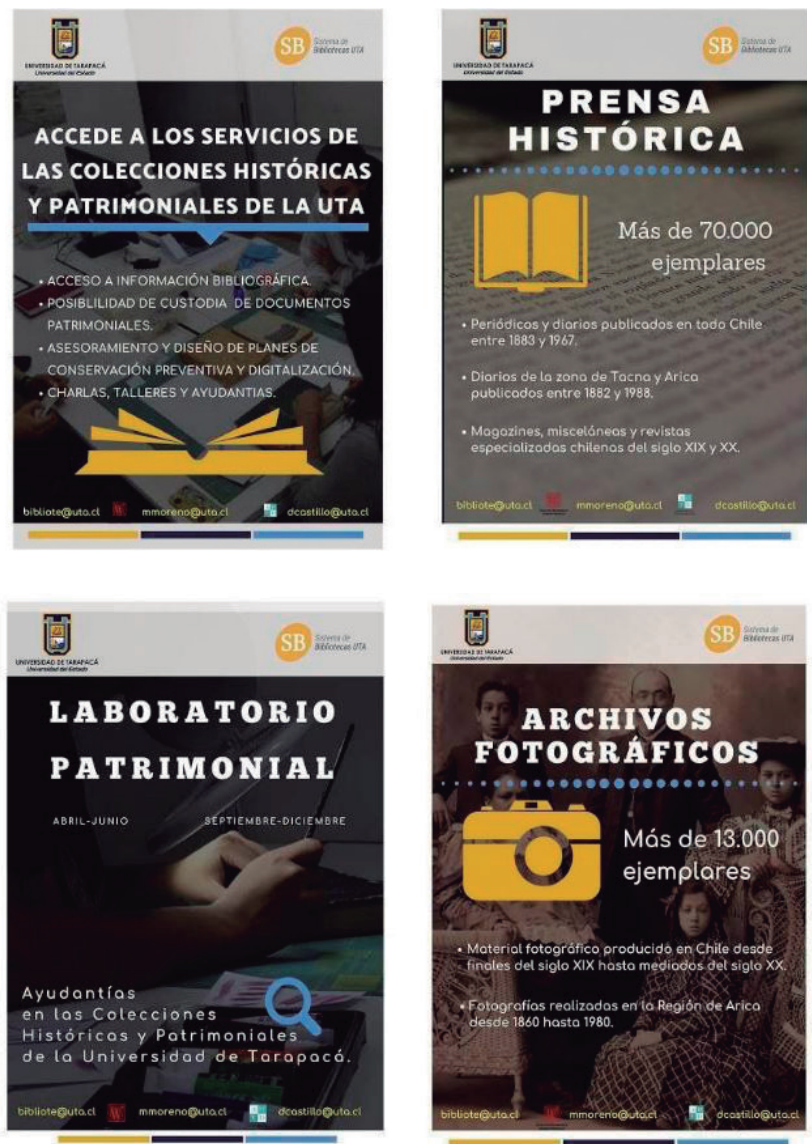

Fuente: Colección Patrimonial Wormald Cruz, 2018. 
Ilustración 3: Visitas y actividades desarrolladas en la Colección Patrimonial Wormald Cruz
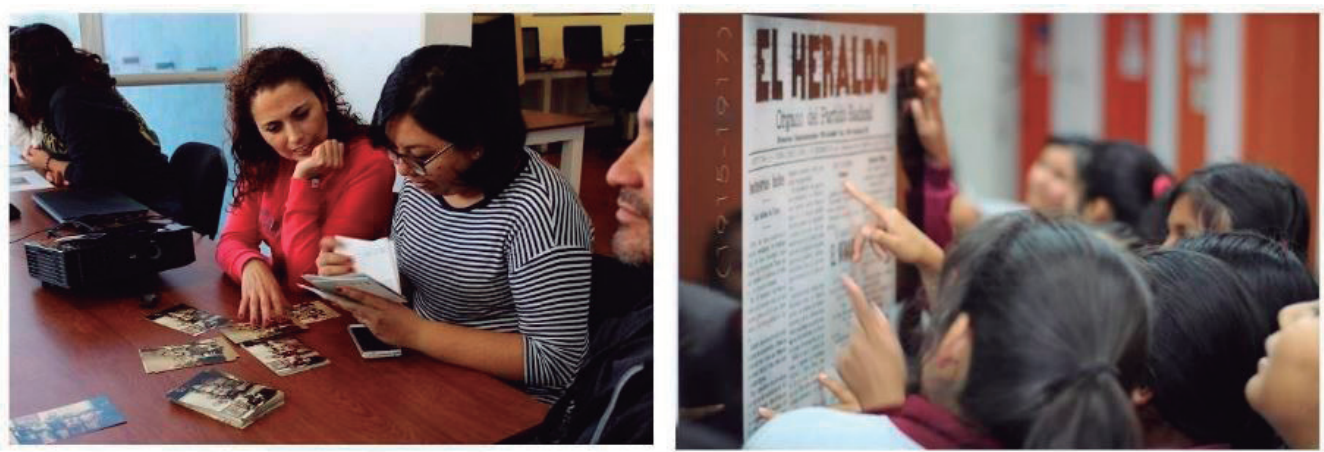

Fuente: Archivo Histórico Vicente Dagnino, 2018.

\section{DISCUSIÓN Y REFLEXIONES FINALES}

El recorrido histórico efectuado a través de la CPWC permite indagar sobre la forma en que se ha entendido la preservación del patrimonio documental en el norte de Chile; las variaciones que han sufrido los diferentes valores asignados a la colección localmente; y la manera en que las líneas epistemológicas definidas por la institución universitaria han condicionado los procesos de patrimonialización de la colección.

Para el caso de estudio analizado, las tres etapas cronológicas revisadas permiten observar diferencias en los valores asignados a los materiales, las actuaciones de patrimonialización desarrolladas y el uso al que han sido destinadas las colecciones. De esta forma, los procesos de patrimonialización se presentan como el resultado de una construcción social, en que las decisiones tomadas institucionalmente por la Universidad han condicionado subjetivamente las relaciones establecidas entre los documentos y el resto de los agentes sociales.

Respecto de los valores asignados a los materiales, en el momento de su adquisición se observa una primacía del valor de la colección como monumento heroico-nacional, el cual fijado inicialmente sufrirá significativas modificaciones hasta la actualidad. A partir de 1980 cobrará cada vez mayor importancia el valor documental de la colección y con el cambio de siglo será más relevante el valor cultural y memorial de los documentos.

En relación a las actuaciones de patrimonialización, si bien en 1960 se observa un marcado interés por adquirir colecciones que ya poseen un reconocido 
valor histórico, a partir de la década de los 90 se abrirá institucionalmente el debate en torno a qué puede ser considerado colección especial. A partir de aquí, primeramente, los historiadores locales y después diversos grupos de la comunidad, tomarán un papel decisivo en la adquisición, ampliación y conformación de nuevas colecciones. Posteriormente, se puede observar cómo en fechas más recientes el foco de interés institucional se desplaza de las actividades de adquisición de nuevas colecciones a las actividades que aseguran la preservación de las ya existentes.

En relación a la accesibilidad de las colecciones, los nuevos usos asignados han supuesto en la práctica un aumento del tipo de visitantes y usuarios. El uso casi exclusivo de historiadores entre 1960-1990, se ha visto complementado con el cambio de siglo por las prácticas y voluntariados efectuados desde la Universidad; las visitas con carácter formativo de escolares y universitarios; el préstamo de espacios y el desarrollo de asesorías para la puesta en valor de archivos locales por parte de la ciudadanía. Es en este contexto de cambio, que distintos grupos y asociaciones pertenecientes a la comunidad han ido adquiriendo legitimidad en la selección y asignación de valores a los bienes patrimoniales, actividad atribuida con anterioridad exclusivamente a la figura del experto.

Si observamos integralmente el conjunto de cambios hasta ahora descritos, el caso de estudio analizado muestra un aumento gradual de los actores involucrados en la toma de decisiones patrimoniales. Este rasgo resultaría esencial en lo que ha sido identificado por algunos autores como paradigma participativo del patrimonio, y si bien este concepto ha sido mucho más trabajado en relación a bienes patrimoniales inmateriales (Quintero y Sánchez 51), lo cierto es que ha modificado por completo las relaciones establecidas entre la sociedad y los archivos-bibliotecas históricas y patrimoniales. Este nuevo paradigma desde el que serían entendidos los procesos de patrimonialización, entraría en conflicto con el mantenimiento del discurso patrimonial autorizado, que entiende que la sociedad debe ser sensibilizada y educada para disfrutar del patrimonio, pero que no está capacitada para participar en los procesos de selección y gestión patrimonial (Quintero y Sánchez 50-58).

En el caso de estudio analizado, nos encontramos con un cambio paulatino y continuado de las funciones desarrolladas institucionalmente para asumir este cambio de paradigma. Los nexos de colaboración establecidos entre los historiadores y los grupos locales para el rescate, visibilización e investigación de nuevas fuentes documentales ha supuesto la inclusión de nuevos actores en los procesos de patrimonialización desarrollados institucionalmente, así como la transformación de las jerarquías tradicionales de selección patrimonial. La 
ampliación de los fondos y colecciones históricas, el ofrecimiento de asesorías, y la capacitación en conservación abierta a la comunidad son ejemplos de las políticas institucionales que han permitido este cambio de paradigma en la gestión de las colecciones documentales.

A su vez, el desarrollo de este tipo de políticas, no habría sido posible sin la inclusión de la figura del conservador-restaurador al trabajo con las colecciones. Su presencia ha posibilitado la planificación y desarrollo local de proyectos de rescate y valorización de nuevos fondos y colecciones y ha problematizado por vez primera los factores específicos implicados en la degradación de colecciones documentales en un entorno climático y social muy distinto al definido desde el centro de Chile.

Cabe preguntarse, si el caso de estudio analizado resulta representativo del panorama actual en que se ven inmersas otras instituciones patrimoniales, o si el papel efectuado por los historiadores locales en la gestión de la CPWC ha influido en la implementación de este tipo de políticas institucionales. No debemos olvidar que el desarrollo de los estudios críticos del patrimonio y la normalización de definiciones patrimoniales que parten de la idea de construcción social del patrimonio si bien ha sido una corriente masivamente aceptada por historiadores y antropólogos, tal y como señalan algunos autores (Sánchez 197), no ha sido el punto de partida para los bibliotecarios, archivistas, gestores patrimoniales y conservadores encargados de la valorización y preservación de bienes patrimoniales.

En resumen, el conjunto de cambios expuestos refleja en la práctica una democratización de los procesos de selección patrimonial que, partiendo de una concepción del patrimonio como un espacio de tensión y disputa discursiva, muestra una fuerte presencia del debate-colaboración entre distintos especialistas y grupos comunitarios. A su vez, como modelo de gestión patrimonial, el caso analizado presenta una complejización en la toma de decisiones asociada a los procesos de puesta en valor. Esta es debida en gran medida a la ruptura del tradicional esquema de separación entre patrimonio material/inmaterial, patrimonio documental/patrimonio popular, institución creadora de patrimonio/ usuarios-consumidores patrimoniales.

Las condiciones hasta aquí expuestas exigen reflexionar acerca de las nuevas funciones del experto en gestión y preservación de colecciones. Los cambios acontecidos parecen indicar la necesidad de establecer una relación dialéctica y no impositiva entre las ideas del restaurador, del historiador y de los diferentes grupos que conforman la sociedad. Ante tales circunstancias, asumir que la toma de decisiones en los procesos de puesta en valor patrimonial está condicionada por factores subjetivos que interesan a cada vez más actores 
sociales se presenta como un punto de partida ineludible. Las interrogantes, ventajas y problemáticas asociadas a estos cambios teóricos son muchas, tanto si una institución abre el debate público en torno a cuáles son las implicaciones sociales que conlleva un plan de puesta en valor y gestión de colecciones documentales, como si no lo hace.

\section{REFERENCIAS BIBLIOGRÁFICAS}

Carta de Atenas. Conservación de monumentos de Arte e Historia. En Conferencia Internacional de Atenas, Grecia, 1931.

Comité Nacional de la Memoria del mundo. Archivos en Chile: miradas, experiencias y desafios. Comité Nacional de la Memoria del Mundo, DIBAM, 2016.

Crespo, Luis. "Restauración de un Cantoral conforme a la estética Wabi Sabi". Conserva, no. 20, 2015, pp. 87-102.

DeSilvey, Caitlin, and Rodney Harrison. "Anticipating loss: rethinking endangerment in heritage futures". International Journal of Heritage Studies, vol. 25, 2019, pp. 1-7. https://doi.org/10.1080/13527258.2019.1644530

Díaz, Alberto, y Elías Pizarro. Arica Siglo XX: Historia y Sociedad en el extremo norte de Chile. Ediciones Universidad de Tarapacá, 2010.

Díaz, Alberto, et al. "Entre el archivo y la etnografía: Reflexiones historiográficas desde la periferia del Norte de Chile". Diálogo andino, no. 46, 2015, pp. 107-121. https://doi.org/10.4067/s0719-26812015000100009

Galdames, Luis, y Alberto Díaz. "La construcción de la identidad ariqueñochilena durante las primeras décadas del siglo XX". Diálogo Andino. Revista de Historia, Geografía y Cultura Andina, no. 29, 2007, pp. 19-28.

Gazmuri, Cristian (2009) La historiografía chilena (1842-1970). Tomo II. Centro de Investigaciones Diego Barros Arana. Ed. Taurus, Santiago.

González, Carolusa. "El restaurador como artista-intérprete". Intervención, no. 1, 2010, pp. 7-15. https://doi.org/10.30763/intervencion.rev1_art4

Guerrero V., Rosa. "Neoliberalismo y patrimonialización. Resistencia y cambio social en procesos de patrimonialización de territorios urbanos del sur de Chile: Biobío, Araucanía y Los Ríos". Scripta Nova: revista electrónica de geografía y ciencias sociales, no. 22, 2018. https://doi.org/10.1344/sn2018.22.20678

ICOMOS. Carta Icomos para la Interpretación y presentación de Sitios de Patrimonio Cultural. ICOMOS, 2008, pp. 1-5. 
López, Juan de Dios. "El patrimonio como constructo político y su potencial reflexivo". PH: Boletín del Instituto Andaluz del Patrimonio Histórico, vol. 24, no. 90, 2016, pp. 218-219. https://doi.org/10.33349/2016.0.3799

Moreno, Mónica, y Daniel Castillo. "El uso de la fotogrametría para la digitalización de documentos cartográficos de gran formato: la experiencia de la Planoteca de la Junta de Adelanto de Arica (PJAA), Chile". Intervención, vol. 9, no. 17, 2018, pp. 80-90. https://doi.org/10.30763/intervencion.2018.17.193

Moreno, Mónica. "Nuevas herramientas para control ambiental en depósitos documentales". Ge-conservación, no. 13, 2018, pp. 68-79. https://doi.org/10.37558/gec.v13i0.531

Muñoz, Salvador. Teoría contemporánea de la Restauración. Editorial Síntesis, 2004.

---. "Réplica a El restaurador como artista-intérprete: Delicias y riesgos de lo artístico". Intervención, no. 1, 2010, pp. 16-18.

---. "Subjetividad y restauración. El argumento del criterio cambiante". Tarea. Anuario del Instituto de Investigaciones sobre el Patrimonio Cultural, no. 1, 2014, pp. 75-87.

Pinochet, Carla. "Reflexiones sobre el patrimonio desde Chile y América Latina". Persona y Sociedad, vol. 32, no. 1, 2018, pp. 1-10.

Quintero, Victoria, y Cristina Sánchez. "Los verbos de la participación social y sus conjugaciones: contradicciones de un patrimonio democratizador". Revista Andaluza de Antropología, no. 12, 2017, pp. 48-69. https://doi.org/10.12795/raa.2017.12.03

Ruz. R., et al. "Historia, patrimonio y fotografía de la Junta de Adelanto de Arica (1958-1976). Exploraciones teórico metodológicas". Arica Siglo XX. Historia y Sociedad en el extremo norte de Chile, compiladores Alberto Díaz, et al., Ediciones Universidad de Tarapacá, 2010, pp. 101-130.

Ruz, Rodrigo, y Luis Galdames. "Historia, archivo y multidisciplina en Chile". Diálogo Andino-Revista de Historia, Geografía y Cultura Andina, no. 46, 2015, pp. 3-8. https://doi.org/10.4067/s0719-26812015000100001

Ruz, Rodrigo, et al. Junta de Adelanto de Arica (1958-1976): Experiencia, documentos e historia regional. Ediciones Universidad de Tarapacá, 2015.

---. "Exotización y alterización del Perú negro en revistas magazinescas chilenas: corre-vuela 1910-1930". Interciencia, vol. 40, no. 11, 2015, pp. 23-40.

Ruz, Rodrigo, et al. "La comisión plebiscitaria Tacna-Arica a través de las caricaturas de la revista sucesos (1925-1926)". Historia 396, vol. 8 no. 1 , 2018, pp. 193-223. 
---. "Magazines Zig-Zag: reportajes gráficos y alteridad en torno al indígena de la nueva frontera norte chilena (1905-1930)". Estudios atacameños, no. 61, 2019 pp. 135-153. https://doi.org/10.4067/s0718-10432019005000401

Sánchez, Cristina. "Hacia una antropología del conflicto aplicada al patrimonio". Geopolíticas patrimoniales. De culturas, naturalezas e inmaterialidades, coordinadora Beatriz Santamarina, Ediciones Neopátria, 2012, pp. 195210.

UNESCO. Memory of the world: general guidelines to safeguard documentary heritage. UNESCO, 2002.

---. Convención para la salvaguarda del patrimonio cultural inmaterial. UNESCO, 2003.

Villaespesa, Elena. "Museum Collections and Online Users: Development of a Segmentation Model for the Metropolitan Museum of Art". Visitor Studies, no. 22, 2019, pp. 233-252. https://doi.org/10.1080/10645578.2019.1668679

\section{Fuentes}

Universidad del Norte, Archivo de la Colección Patrimonial Alfredo Wormald Cruz. Carta emitida por Agustín Sánchez Hurtado (Vice-Rector) y enviada a Gabriel Hernández Anderson. Emitido el 16 de marzo de 1968. Sin Publicar.

Archivo de la Colección Patrimonial Alfredo Wormald Cruz. Carta emitida por Gabriel Hernández Anderson y enviada a Teodoro Schmidt (Gerente General de la J.A.A). Emitido el 5 de enero de 1974. Sin Publicar.

Archivo de la Colección Patrimonial Alfredo Wormald Cruz. Carta emitida por Gabriel Hernández Anderson y enviada al coronel Hernán Danyau Quintana (Rector de la Universidad del Norte, sede Antofagasta). Emitido el 5 de enero de 1974. Sin Publicar.

Archivo de la Colección Patrimonial Alfredo Wormald Cruz. Carta emitida por Gabriel Hernández Anderson y enviada a Manuel Castillo Ibaceta (Alcalde de la Municipalidad). Emitido el 5 de enero de 1974. Sin Publicar.

Archivo de la Colección Patrimonial Alfredo Wormald Cruz. Carta emitida por Gabriel Hernández Anderson y enviada a Odlanier Mena Salinas (Gobernador Departamental y Jefe Militar de la Guarnición). Emitido el 5 de enero de 1974. Sin Publicar.

Archivo de la Colección Patrimonial Alfredo Wormald Cruz. Lista de publicaciones periódicas recolectadas por el servicio de Inteligencia, Arica. Sin Publicar. 
Biblioteca de Arica, Universidad del Norte, Archivo de la Colección Patrimonial Alfredo Wormald Cruz. Libros retirados por el servicio de inteligencia, regimiento de Rancagua, 19 y 20 de septiembre de 1973. Emitido el 24 de septiembre de 1973. Sin Publicar.

CIDH (Centro de Investigación y Documentación Histórica), Universidad del Norte, Sede Arica. Boletín bibliográfico: Papeles de J. T. North. Emitido en septiembre de 1977. Sin Publicar. 